\title{
Setting a Precautionary Catch Limit for Antarctic Krill
}

\author{
Roger P. Hewitt' \\ Jon L. Watkins ${ }^{2}$ \\ Mikio Naganobu ${ }^{3}$ \\ Pavel Tshernyshkov' \\ Andrew S. Brierley ${ }^{5}$ \\ David A. Demer? \\ Svetlana Kasatkina \\ Yoshimi Takao ${ }^{\circ}$ \\ Cathy Goss ${ }^{2}$ \\ Alexander Malyshko ${ }^{4}$ \\ Mark A. Brandon 7 \\ So Kawaguchi ${ }^{3}$ \\ Volker Siege ${ }^{\beta}$ \\ Philip N. Trathan ${ }^{2}$ \\ Jennifer H. Emery' \\ Inigo Everson ${ }^{2}$ \\ Denzil G.M. Miller \\ 'NOAA/Southwest Fisheries Science Center • La Jolla, California USA \\ ${ }^{2}$ British Antarctic Survey. Cambridge UK \\ ${ }^{3}$ National Research Institute of Far Seas Fisheries - Shimizu Japan \\ ${ }^{4}$ AtlantNIRO . Kaliningrad Russia \\ ${ }^{5}$ Gatty Marine Laboratory, University of St. Andrews - Fife Scotland \\ 'National Research Institute of Fisheries Engineering • Ibaraki Japan \\ 'The Open University. Milton Keynes UK \\ ${ }^{8}$ Institut für Seefischerei · Hamburg Germany \\ 'Marine and Coastal Management · Roggebaai South Africa
}

\section{Abstract}

A revised precautionary catch limit for Antarctic krill (Euphausia superba) in the Scotia Sea of 4 million tons was recently adopted by the Commission for the Conservation of Antarctic Marine Living Resources (CCAMLR). The limit was based on a total biomass of 44.3 million tons, as estimated from an acoustic and net survey of krill across the Scotia Sea sector of the Southern Ocean, and a harvest rate of $9.1 \%$, as determined from an analysis of the risks of exceeding defined conservation criteria. We caution, however, that before the fishery can expand to the 4-million-ton level it will be necessary to establish mechanisms to avoid concentration of fishing effort, particularly in proximity to colonies of land-breeding krill predators, and to consider the effects of krill immigrating into the region from multiple sources.

The Antarctic Circumpolar Current (ACC) concentrates and accelerates as it passes through Drake Passage transporting massive quantities of water from the Bellingshausen Sea (southeast Pacific) to the Scotia Sea (southwest Atlantic) sectors of the Southern Ocean. High concentrations of Antarctic krill (Euphausia superba) and krill predators are located in this region (Marr, 1963; Laws, 1985) as well as an international fishery targeting krill (Agnew and Nicol, 1996). The fishery is regulated under the Convention for the Conservation of Antarctic Marine Living Resources (CAMLR), part of the Antarctic Treaty system (Box 1). Article II of Convention mandates that fisheries be managed such that: a) the size of harvested populations is sufficient to ensure stable recruitment; b) ecological relationships between harvested and dependent populations are maintained; and c) changes to the marine ecosystem that cannot be reversed over two or three decades are prevented. In order to meet this charge CCAMLR adopted a precautionary approach whereby the provi- 
sions of Article II were more specifically defined and risks were quantitatively assessed (Butterworth et al., 1992; Constable et al., 2000).

The approach is to set the proportion of the unexploited biomass that can be harvested under specific management criteria (Box 2). Risks are evaluated by comparing statistical distributions of population biomasses generated from simulated population trajectories, with and without fishing mortality. Uncertainty is accommodated by using values of abundance, recruitment, growth and mortality drawn from appropriate statistical distributions. The first criterion is to protect the viability of the harvested population and for Antarctic krill is defined such that the probability that the population biomass falls to less than $20 \%$ of its unexploited median level should be less than $10 \%$. The second criterion is to protect the viability of krill predator populations and is defined such that the median population level should be at least $75 \%$ of the unexploited median population level. The third criterion is to evaluate these risks using population trajectories that extend at least 20 years. The value of the harvest rate, expressed as a proportion of the unexploited biomass that meets these criteria is accepted as the most precautionary. This value together with an estimate of the unexploited population biomass is used to set the precautionary catch limit for krill. Initially, an estimate of krill biomass was generated from acoustic data collected during the first international BIOMASS experiment (FIBEX) ${ }^{1}$ in 1981 (Trathan et al., 1992), the only large-scale acoustic survey in this region prior to 2000 .

Our motivations for conducting a new acoustic survey were threefold. The first was the recognition of several technical improvements

\section{Box 1}

\section{What is CCAMLR?}

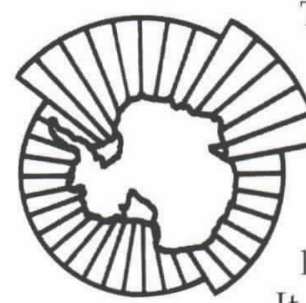

The Convention for the Conservation of Antarctic Marine Living Resources was negotiated by the Antarctic Treaty Consultative Parties in the late 1970s and entered into force in 1982 with a permanent Secretariat located in Hobart, Tasmania, Australia. It is widely acknowledged that the Convention was the first international fisheries agreement to mandate an ecosystem approach to resource management, and that its Commission (CCAMLR) was the first to formally incorporate uncertainty into the formulation of management advice, the first to implement conservation measures designed to reduce catastrophic by-catches of seabirds, and the first to effectively address illegal, unregulated and unreported (IUU) fishing of Patagonian toothfish (widely marketed in North America as Chilean seabass) through a catch documentation scheme. The meetings of Scientific Committee of CAMLR and its Working Groups are the venues where such initiatives are developed and tested, where management advice is formulated, and where full participation by member nations is highly valued. Conservation measures are adopted by CCAMLR by consensus, but implemented and enforced by Members. Currently there are 24 Members of the Commission (Argentina, Australia, Belgium, Brazil, Chile, European Community, France, Germany, India, Italy, Japan, Korea, Namibia, New Zealand, Norway, Poland, Russia, South Africa, Spain, Sweden, Ukraine, UK, USA and Uruguay) with another seven nations (Bulgaria, Canada, Finland, Greece, Netherlands, Peru and Vanuatu) acceding to the tenets of the Convention.

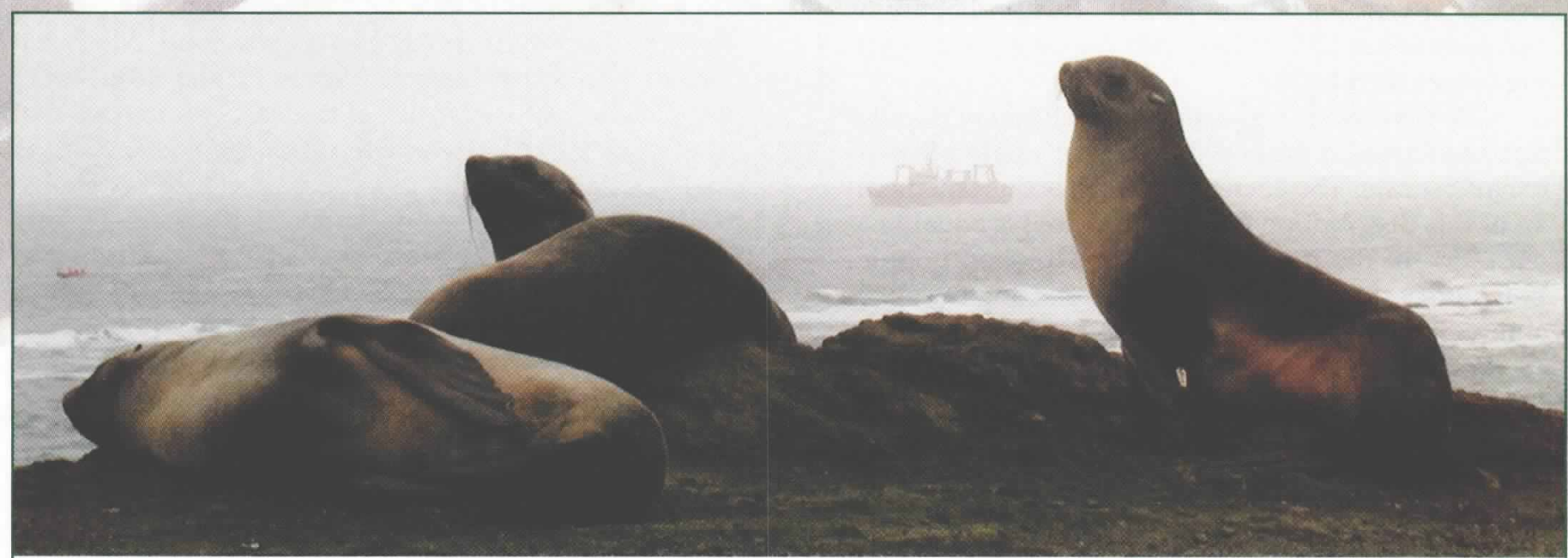

Fur seals and research vessel off Cape Shirreff. Photo by M. Goebel.

In the early 1980s the Scientific Committee for Antarctic Research (SCAR) organized the BIOMASS Program (Biological Investigations of Antarctic Systems and Stocks). FIBEX (First International BIOMASS Experiment) was a multi-national multi-ship effort to conduct large-scale acoustic surveys over large areas of the Southern Ocean. See also El-Sayed (1994). 
Box 2

\section{Evaluating the risk of exceeding defined conservation criteria.}

In principle, CCAMLR has adopted a feedback approach to management of the krill fishery, by which management measures are adjusted in response to ecosystem monitoring. However, such a management scheme remains to be fully developed. In the interim, a complementary approach, which defined and implemented provisions of Article II of the Convention in reference to the Scotia Sea krill stock, was adopted in order to set a precautionary catch limit. Once specific management objectives and the criteria for achieving them were agreed to in the policy arena the analysis of risk and provision of advice could be accomplished with less ambiguity.

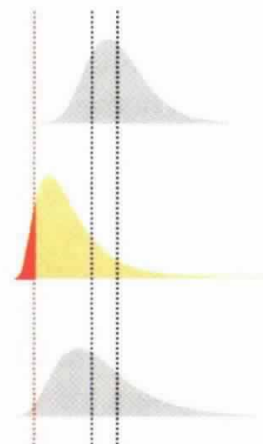

0.250500751001251 .50

Biomass relative to median unexploited biomass
The frequency distributions of simulated population sizes (left) illustrate the approach for Antarctic krill and are reproduced from a recent paper by Constable et al. (2000).

The first is the frequency distribution of unexploited population biomass obtained from an age structured population model that incorporates variability for growth, mortality and initial population biomass. The black dotted line indicates the median of the distribution.

The second is the frequency distribution of lowest population biomasses achieved during each of the 20 -year trajectories under a specific harvest rate. The red area represents the probability of biomass declining below $20 \%$ of the unexploited median biomass over a 20-year harvesting period. This probability is currently set at $10 \%$ or less with the intent of protecting future recruitment.

The third is the frequency distribution of population biomasses at the end of a 20-year under a specific harvest rate. The current criterion is that the median of this distribution (blue dotted line) is equal to at least $75 \%$ of the median of the unexploited population biomasses with the intent of protecting the availability of prey to krill predators.

For krill in the Scotia Sea, the harvest rate meeting these criteria was $9.1 \%$. The criteria are somewhat arbitrary and may be adjusted as more information becomes available regarding the relationships between krill population biomass, recruitment and predator response. The approach, however, allows for the incorporation of natural variability in population parameters and uncertainty in their estimation in the evaluation of risk associated with various harvest rates. since the conduct of the FIBEX survey in the assessment of krill biomass using active acoustic methods (Everson et al., 1990; Greene et al., 1991; Hewitt and Demer, 1991). The second was the recognition that the FIBEX survey area was substantially less than the known habitat of krill in the Scotia Sea. And the third was the recognition that the krill population in the Scotia Sea may not be stable. Recently published evidence suggests that krill reproductive success may be dependent on multi-year changes in the physical environment (Loeb et al., 1997; Nicol et al., 2000; White and Petersen, 1996; Nagunobu et al., 1999; Brierley et al., 1999): during periods of equatorward excursions of the southern boundary of the ACC, the development of winter-time sea ice (the underside of which is postulated to provide access to ice algae and refuge from predators for over-wintering adult and larval krill) is more extensive, populations of Salpa thompsoni (a pelagic tunicate postulated to be a competitor with krill for access to the spring-time phytoplankton bloom) are displaced offshore, and both krill reproductive output and survival of their larvae are enhanced. During periods of poleward excursions of the southern boundary of the ACC, the development of winter-time sea ice is less extensive, salps are more abundant closer to shore and krill reproductive success is depressed. These interactions may be confounded by a warming trend observed in the Antarctic Peninsula over the last 50 years (Vaughn and Doake, 1996). We wanted to anchor the estimate of precautionary yield with the most recent and most accurate assessment of Antarctic krill in the Scotia Sea that was possible. Because historical harvest rates have been low relative to the size of the fished resource, we assumed that an estimate of the current standing stock was equivalent to the unexploited spawning biomass.

The defining physical feature of the Scotia Sea is its southern boundary along the Scotia Ridge, extending from the South Shetland Islands east and north through the South Orkney Islands, the South Sandwich Islands and South Georgia (Figure 1), and influencing the direction and intensity of the ACC. Antarctic krill appear to move eastward through the Scotia Sea via the ACC, although the relative importance of passive transport versus active migration is uncertain. Likely sources of immigrants are the Bellingshausen Sea to the west and the Weddell Sea to the south. Differences in mitochondrial DNA sequences suggest that krill from these regions may be genetically distinct (Zane et al., 1998). Within the Scotia Sea, zones of water convergence, eddies and gyres are loci for krill concentrations (Witek et al., 1988; Makarov et al., 1988). Krill spawn in the vicinity of the South Shetland and South Orkney Islands. Although they are abundant further to the north and east near South Georgia, they do not successfully reproduce there (Fraser, 1936). Consumption of krill throughout the Scotia Sea by baleen whales, crabeater and fur seals, pygoscelid penguins and other 
(a)

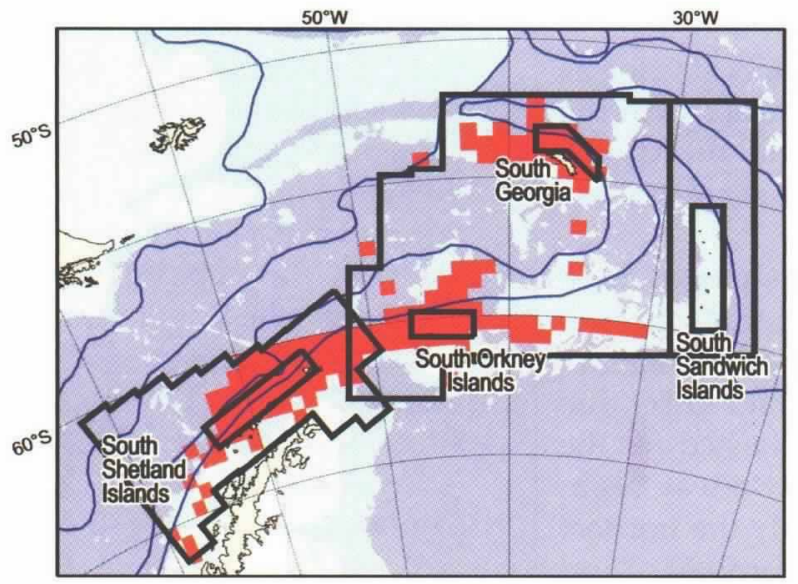

(b)

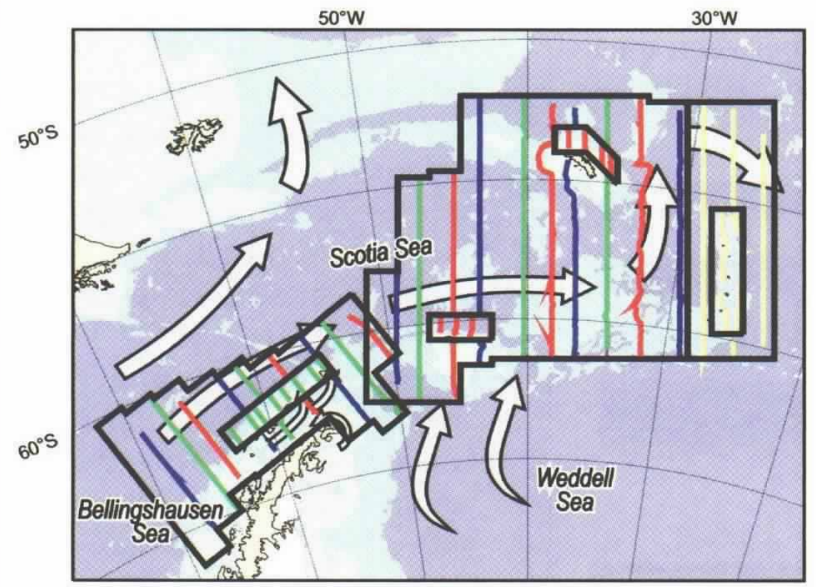

Figure 1. Island groups and bathymetry of the Scotia Sea (shading indicates $500 \mathrm{~m}, 1000 \mathrm{~m}$, and $3000 \mathrm{~m}$ isobaths). (a) Survey strata outlined in black relative to historical fishing activity (red squares) and major ocean frontal zones (blue lines; from north to south, the Sub-Antarctic Front, the Polar Front, the Southern ACC Front, and the southern ACC Boundary). (b) Survey transects color coded, where green indicates those transects occupied by the Japanese $R / V$ Kaiyo Maru, yellow indicates the Russian R/V Atlantida, blue indicates the British RRS James Clark Ross, and red indicates the US chartered $R / V$ Yuzhmorgeologiya. Arrows indicate direction of major currents.
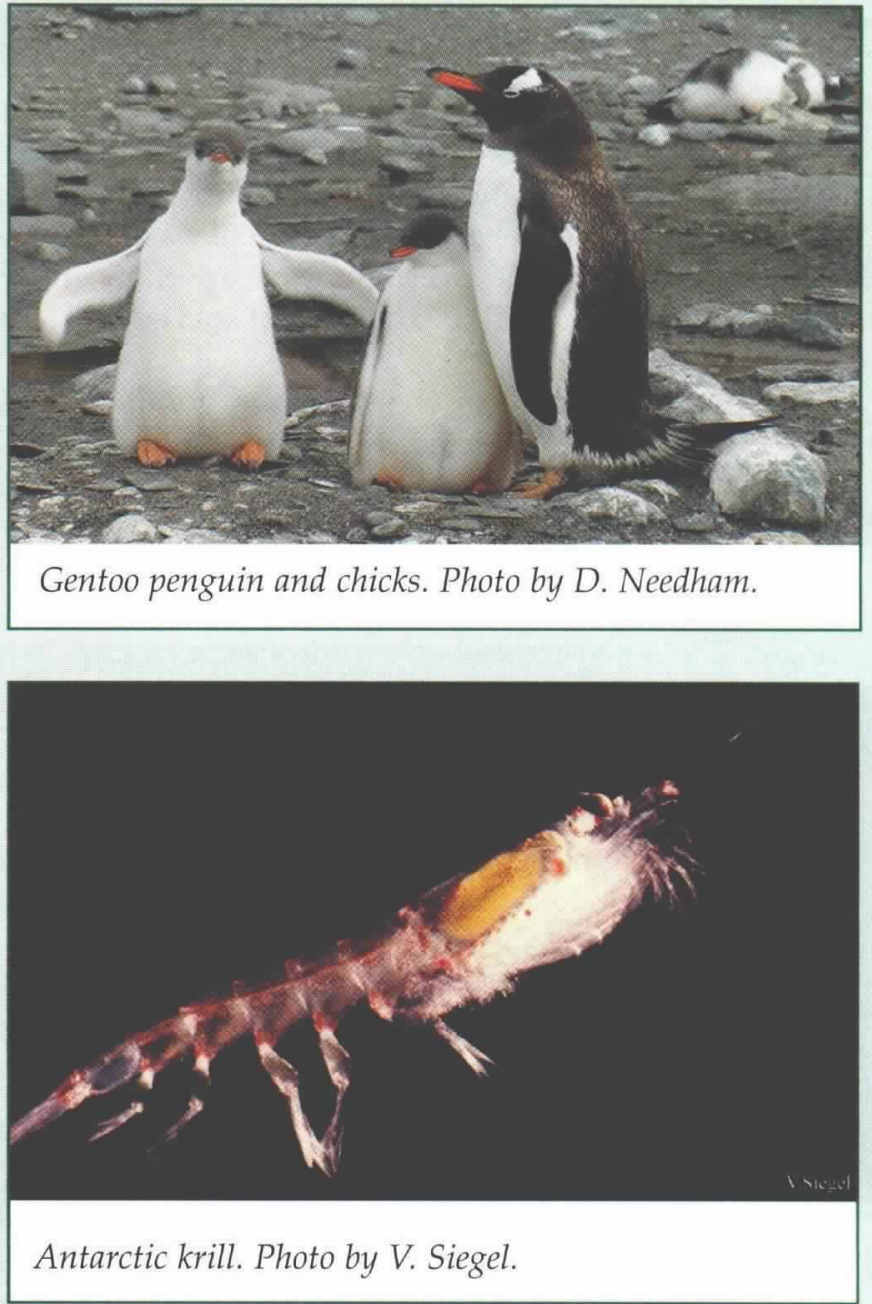

sea birds, squid and fish is estimated to be between 16 and 32 million tons per annum (Everson and de la Mare, 1996). Although higher in previous years, annual harvests of krill since 1992 have averaged approximately 100,000 tons ${ }^{2}$. Fishing effort has been concentrated near the shelf breaks along the north side of the South Shetland, South Orkney and South Georgia archipelagos (Agnew and Nicol, 1996).

The survey area extended across the Scotia Sea and included the continental shelves, oceanic regions, the major frontal zones associated with the ACC and the principal areas of fishing activity (Figure 1a). The survey design consisted of seven strata (four island strata and three oceanic strata, Figure 1b) with randomly spaced parallel transects within each stratum (Trathan et al., 2001). The mean density on a transect within a stratum, as determined from acoustic sampling of krill (Box 3), was considered to be a representative sample of the mean density of the stratum (Jolly and Hampton, 1990). Each vessel also obtained net samples and profiles of oceanographic parameters on stations conduct-

${ }^{2}$ Harvest statisics for Antarctic krill are maintained by the CCAMLR Secretariat, P.O Box 213, North Hobart 7002, Tasmania, Australia. email: ccamlr@ccamlr.org; website: www.ccamlr.org 


\section{Delineating acoustic return from krill.}

Echosounders have been used since the 1940s to locate fish and qualitatively assess their abundance. Since the 1960s, however, their practical value as a quantitative tool for stock assessment has increased dramatically with the availability of digital electronics, cheap computing power and the Global Positioning System (GPS). The current survey took advantage of some of these developments:

On each survey vessel samples of volume backscattering strength at 38 and $120 \mathrm{kHz}$ were collected; vertical resolution was $0.71 \mathrm{~m}$ from transducer to $500 \mathrm{~m}$ depth and horizontal resolution was approximately $10 \mathrm{~m}$ (ping interval was $2 \mathrm{sec}$ while steaming at $10 \mathrm{knots}$ ). These data were corrected for losses due to spherical spreading and absorption of sound energy and adjusted for the effects of temperature on acoustic wavelength and equivalent two-way beam angle. The reconstructed echograms were filtered to include only the transect periods between stations and to exclude echoes due to surface turbulence and the bottom (first two panels).

Echograms were then resampled by averaging volume backscattering strength over $5 \mathrm{~m}$ (vertical) by $500 \mathrm{~m}$ (horizontal) bins. Time-varied echograms of pure noise were generated and subtracted from the resampled echograms. In this example the primary sound reflectors are aggregations of Antarctic krill and myctophid fish (second two panels).

Backscattering was attributed to krill when the difference between mean volume backscattering at $120 \mathrm{kHz}$ and $38 \mathrm{kHz}$ was greater than $2 \mathrm{~dB}$ but less than $16 \mathrm{~dB}$ (Watkins and Brierley, 2000).

This was accomplished by subtracting the $38 \mathrm{kHz}$ noise-free resampled echogram from the $120 \mathrm{kHz}$ noise-free resampled echogram. Portions of the $120 \mathrm{kHz}$ noisefree resampled echogram were then masked to exclude regions where the difference between the mean volume backscattering strength at $120 \mathrm{kHz}$ and that at $38 \mathrm{kHz}$ was less than $2 \mathrm{~dB}$ or greater than $16 \mathrm{~dB}$ (lower of third set of panels).

In the final steps the masked noise-free resampled $120 \mathrm{kHz}$ echograms were vertically integrated $500 \mathrm{~m}$ depth and averaged over 1 nautical mile horizontal distance (upper of third set of panels). Integrated volume backscattering area was converted to area krill density by applying a factor equal to the quotient of the weight of an individual krill and its backscattering cross-sectional area summed over the length frequency distribution (Hewitt and Demer, 1993). Conversion factors were calculated for each length frequency cluster and applied to the appropriate segments of each transect. Area krill density values were under-weighted by the degree to which the survey vessel deviated from the intended transect direction.
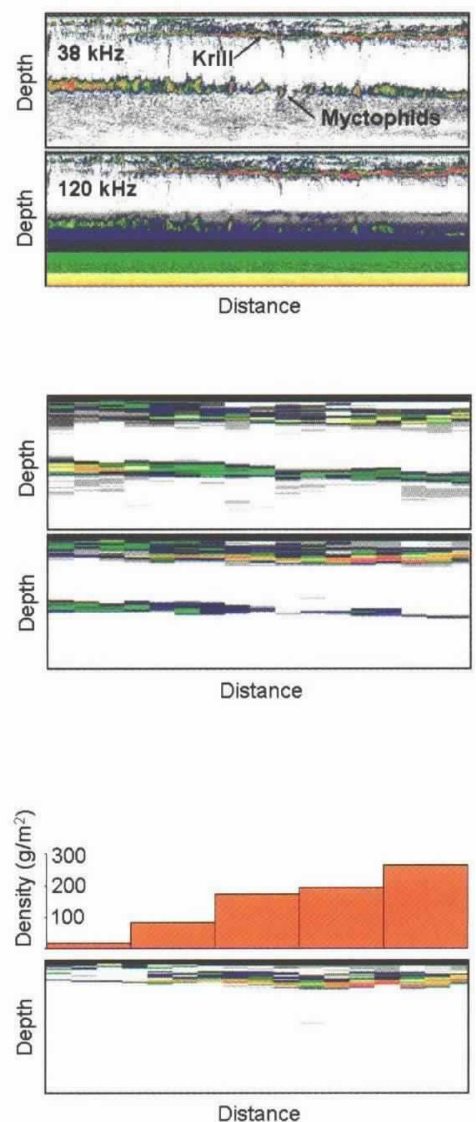

ed at local apparent noon and midnight. These three data sets (acoustic samples, net samples, and oceanographic profiles) were considered to be the core data sets of the survey and we agreed to analyze and report them in a collaborative fashion. We report here the first of our analyses, the standing stock of krill across the Scotia Sea. ${ }^{3}$

Highest densities of krill were encountered in the island strata, ranging from $25.8 \mathrm{~g} \mathrm{~m}^{-2}$ (CV 26.4\%) near the South Sandwich Islands to $150.4 \mathrm{~g} \mathrm{~m}^{-2}$ (CV 55.5\%) near the South Orkney Islands; densities in the oceanic strata ranged from $11.2 \mathrm{~g} \mathrm{~m}^{-2}$ (CV 19.3\%) off the Antarctic Peninsula to $24.54 \mathrm{~g}$ $\mathrm{m}^{-2}$ (CV $\left.15.3 \%\right)$ in the western Scotia Sea; total krill biomass over the survey area was estimated at 44.3 million tons (CV $11.4 \%$ ) (Table 1). The coefficients of variation reported here represent sampling uncertainty as opposed to measurement uncertainty (Hewitt and Demer, 2000). David Demer (pers. comm.) has undertaken an analysis of the total uncertainty associated with the survey including errors associated with system calibration, characterization of krill target strength, probability of detection, and the efficiency of algorithms used to delineate backscatter attributed to krill; he concluded that measurement variance was negligible relative to sampling variance, but that uncertainty with regard to krill target strength remains the largest source of potential bias. ${ }^{3}$ Small krill (1-2 years old, $26 \mathrm{~mm}$ modal length) were mapped in the eastern portion of the Scotia Sea in a broad tongue extending from the southern part of the survey area between the South Orkney and South Sandwich Islands

${ }^{3}$ Copies of the CCAMLR 2000 Survey core data sets are maintained by the CCAMLR Secretariat. Rules of access to CCAMLR data are available from the CCAMLR website. Any scientist from a member country can request access to the data through that country's representative to the Scientific Committee. A collection of papers describing various aspects of the survey is expected to be published in a special issue of Deep Sea Research II. 
Table 1

Krill density and biomass estimates by strata.

Stratum

1. Antarctic Peninsula

2. Scotia Sea

3. East Scotia Sea

4. South Shetland Islands

5. South Orkney Islands

6. South Georgia

7. Sandwich Islands
Mean krill density $\left(\mathrm{g} / \mathrm{m}^{2}\right)$

11.2

24.5

11.3

37.7

150.4

39.3

25.8

21.4

Area Surveyed
$\left(10^{3} \mathrm{~km}^{2}\right)$

473.3

1109.8

321.8

48.6

24.4

25.0

62.3

2065.2

Biomass
$\left(10^{3}\right.$ tons $)$

5320

27235

3642

1836

3670

982

1604

44289
Coefficient of

Variation (\%)

19.3

15.3

42.5

26.2

55.5

30.8

26.4

11.4

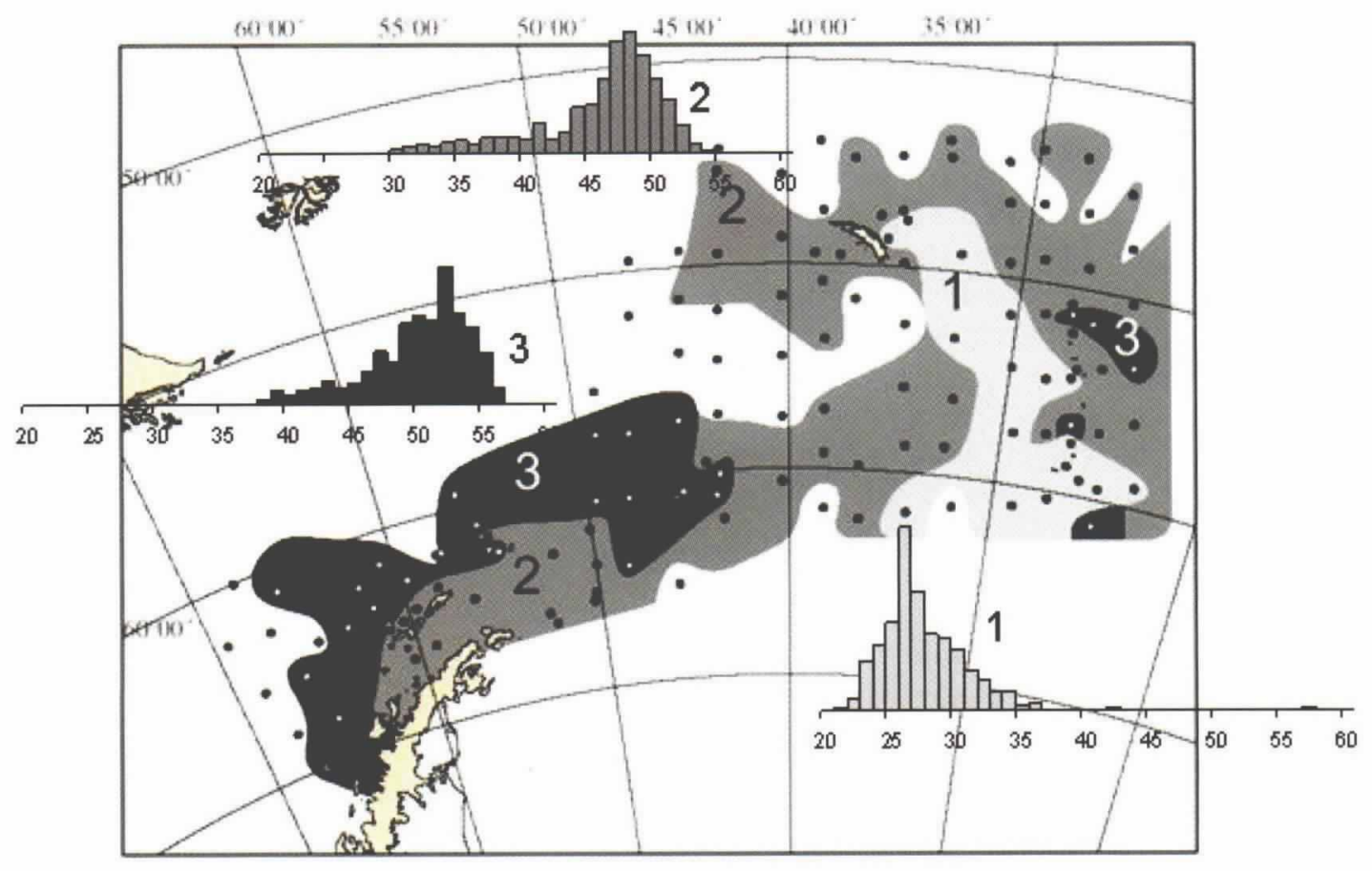

Figure 2. Composite krill length-frequency distributions and the geographic distribution of stations for each cluster as defined by Volker Siegel (pers. comm.). Note the broad band of small, 1-2 year old krill extending into the eastern portion of the Scotia Sea from the Weddell Sea, while larger, 3-6 year old krill were encountered in other portions of the surveyed area. Krill were sampled on each survey vessel using a Rectangular Midwater Trawl (Baker et al., 1973) with an $8 \mathrm{~m}^{2}$ mouth opening and 4.5 $\mathrm{mm}$ mesh. The net was retrieved from $200 \mathrm{~m}$ depth at a constant rate of $0.3 \mathrm{~m} \mathrm{sec}^{-1}$ while the ship was moving forward at 2.5 \pm 0.5 knots. A flow meter and a real-time time depth recorder were attached to determine the volume of water filtered and the net trajectory. Sub-samples of at least $100 \mathrm{krill}$ were taken from each catch for length measurements and maturity stage identification (Makarov and Denys, 1981); all krill were examined from catches of less than 100 specimens. A cluster analysis was conducted by computing a similarity matrix, based on the relative frequency of each krill length class at each station, and subsequently fusing clusters using the Euclidean distance coefficient as measure of similarity. Only stations with a minimum of 20 measured specimens were considered; 66 out of 135 stations were included in the similarity matrix. Station-specific length frequency distributions were weighted by catch and the volume of water filtered before compiling the composite lengthfrequency distributions shown here. 
north to the eastern end of South Georgia; very large krill (4-6 years old, $52 \mathrm{~mm}$ modal length) were mapped in the western Scotia Sea and Drakes Passage; a third cluster of large krill (3-5 years old, $48 \mathrm{~mm}$ modal length, but also including several samples of intermediate size krill) was mapped in the inshore waters adjacent to the Antarctic Peninsula and extended across the northeastern part of the survey area (Figure 2).

The estimate of krill biomass in the Scotia Sea, together with a harvest rate of $9.1 \%$, was used to establish a potential yield of 4 million tons (CAMLR-XIX, 2000). The population model underlying the simulations assumes a freely distributed krill population, homogeneously distributed predation pressure and randomly determined recruitment. The effects of uncertainty with regard to input parameters are included, but spatial and temporal trends in krill demographics, predator demand and fishing pressure are not (Hewitt and Linen Low, 2000). Several members of CCAMLR are conducting research studies and long-term monitoring in order to provide some of this information (Agnew, 1997), but until a more spatially explicit management scheme is in place the regionwide model will remain the primary tool for setting population-wide harvest rates.

Before the fishery can expand to the 4-million-ton level, however, it will be necessary to establish mechanisms to avoid concentration of fishing effort near colonies of land-breeding krill predators. The Scientific Committee of CAMLR is currently investigating how such mechanisms may be rationalized by the establishment of small-scale management units. These data also suggest that krill resident in the Scotia Sea may come from more than one source, further complicating management considerations.

The precautionary approach to the management of the krill fishery adopted by CCAMLR provides a method by which uncertainty in parameter estimates can be explicitly included in the estimate of harvest rate. The framework is flexible and can accommodate restatement of management objectives and reformulation of the criteria used to ensure that the objectives are met. Moreover, the approach allows separation of the political process of setting management objectives and criteria from the technical process of running the population simulations and determining the harvest rate. This approach was developed over several years by Doug Butterworth, Bill de la Mare, Andrew Constable and their colleagues and is now referred to as the Generalized Yield Model (GYM). Use of the GYM to manage the krill fishery, however, was adopted by CCAMLR as an interim measure to its preferred approach: a feedback scheme whereby management measures are adjusted in response to ecosystem monitoring (Constable et al., 2000). The full development of this approach will require: 1) enhancement of CCAMLR's existing ecosystem monitoring program; 2) further development of models linking krill, their

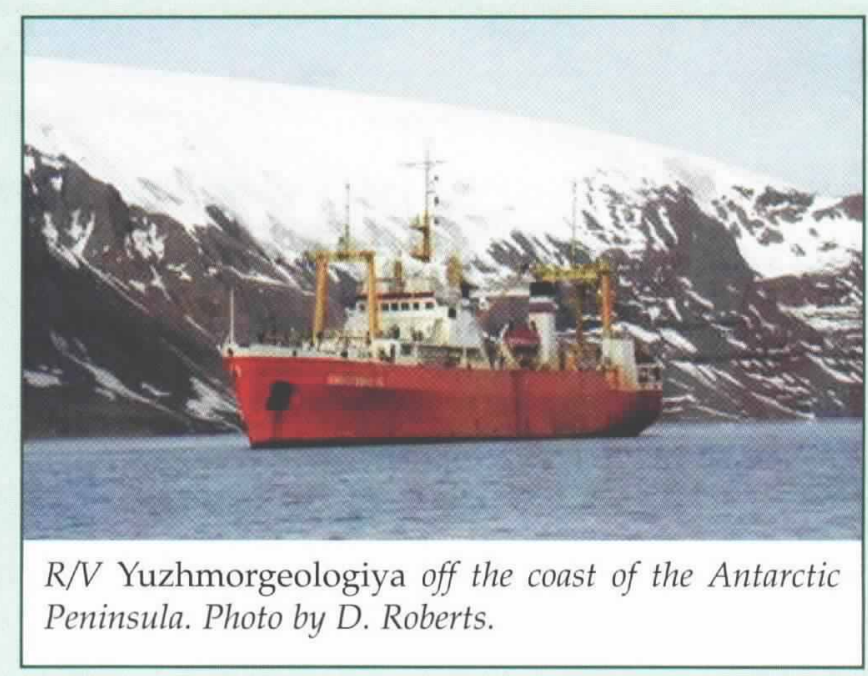

predators, environmental influences and the fishery; and 3) high-resolution, real-time information regarding the behavior of fishing vessels.

\section{References}

Agnew, D.J., 1997: Review: The CCAMLR ecosystem monitoring program. Antarctic Science, 9(3), 235-242.

Agnew, D.J. and S. Nicol, 1996: Marine disturbancescommercial fishing. In: Foundations for Ecological Research West of the Antarctic Peninsula. R.M. Ross, E.E. Hoffmann and L.B. Quentin, eds., Antarctic Research Series Volume 70. American Geophysical Union, Washington D.C., 417-435.

Baker, A. deC., M.R. Clarke and M.E. Harris, 1973: The N.I.O. combination net (RMT 8+1) and further developments of rectangular midwater trawls. $J$. Mar. Biol. Assoc. UK, 53, 176-184.

Brierley, A.S., D.A. Demer, J.L. Watkins and R.P. Hewitt, 1999: Concordance of interannual fluctuations in acoustically estimated densities of Antarctic krill around South Georgia and Elephant Islands: biological evidence of same-year teleconnections across the Scotia Sea. Mar. Biol., 134(4), 675-681.

Butterworth, D.S., A.E. Punt and M. Basson, 1992: A simple approach for calculating the potential yield of krill from biomass survey results. In: Selected Scientific Papers (SC-CAMLR-SSP/8). CCAMLR, Hobart, Australia, 207-217.

CAMLR-XIX, 2000: Report of the Nineteenth Meeting of the Commission. CCAMLR, Hobart, Australia.

Constable A.J., W.K. de la Mare, D.J. Agnew, I. Everson and D. Miller, 2000: Managing fisheries to conserve the Antarctic marine ecosystem: practical implementation of the Convention on the Conservation of Antarctic Marine Living Resources (CCAMLR). ICES Jour. Mar. Sci., 57, 778-791.

El-Sayed, S.Z., ed., 1994: Southern Ocean Ecology: the BIOMASS perspective. Cambridge Univ. Press, $399 \mathrm{pp}$.

Everson, I., J.L. Watkins, D.G. Bone and K.G. Foote, 1990: Implications of a new acoustic strength for 
abundance estimates of Antarctic krill. Nature, 345, 338-340.

Everson, I., and W.F. de la Mare, 1996: Some thoughts on precautionary measures for the krill fishery. CCAMLR Science, 3, 1-11.

Fraser, F.C., 1936: On the development and distribution of young stages of krill (Euphausia superba). Discovery Rep., 14, 1-192.

Greene, C.H., T.K. Stanton, P.H. Wiebe and S. McClatchie, 1991: Acoustic estimates of Antarctic krill. Nature, 349, 110.

Hewitt, R.P. and D.A. Demer, 1991: Krill abundance. Nature, 353, 310.

Hewitt, R.P. and D.A. Demer, 1993: Dispersion and abundance of krill in the vicinity of Elephant Island in the 1992 austral summer. Mar. Ecol. Prog. Ser., 99, 29-39.

Hewitt, R.P. and D.A. Demer, 2000: The use of acoustic sampling to estimate the dispersion and abundance of euphausiids, with an emphasis on Antarctic krill, Euphausia superba. Fisheries Research, 47, 215-229.

Hewitt, R.P. and E.H. Linen Low, 2000: The fishery on Antarctic krill: Defining an ecosystem approach to management. Reviews in Fishery Science, 8(3), 235-298.

Jolly, G.M. and I. Hampton, 1990: A stratified random transect design for acoustic surveys of fish stocks. Can. J. Fish. Aquat. Sci., 47, 1282-1291.

Laws, R.M., 1985: The ecology of the Southern Ocean. Am. Scient., 73, 26-40.

Loeb, V., V. Siegel, O. Holm-Hansen, R. Hewitt, W. Fraser, W. Trivelpiece and S. Trivelpiece, 1997: Effects of sea-ice extent and krill or salp dominance on the Antarctic food web. Nature, 387, 897-900.

Makarov, R.R. and C.J.I. Denys, 1981: Stages of sexual maturity of Euphausia superba. BIOMASS Handbook, 11,13 pp.

Makarov, R.R., V.V. Maslennikov, E.V. Solyankin, V.A. Spiridonov and V.N. Yakovlev, 1988: Variability in population density of Antarctic krill in the Western Scotia Sea in relation to hydrological conditions. In: Antarctic Ocean and Resources Variability. Springer Verlag, 231-236.

Marr, J.W.S., 1963: The natural history and geography of the Antacrtic krill (Euphausia superba). Discovery Rep., 32, 33-464.

Naganobu, M., K. Kutsuwada, Y. Sasai, S. Taguchi and V. Siegel, 1999: Relationships between Antarctic krill (Euphausia superba) variability and westerly fluctuations and ozone depletion in the Antarctic Peninsula area. J. Geophys. Res., 104(C9), 20651-20665.

Nicol, S, T. Pauly, N.L. Bindoff, S. Wright, D. Thiele, G.W. Hosie, P.G. Strutton and E. Woehler, 2000: Ocean circulation off east Antarctica affects ecosystem structure and sea-ice extent. Nature, 406, 504-507.

Trathan, P.N., D.J. Agnew, D.G.M. Miller, I.E.J.L. Watkins, M.R. Thorley, E. Murphy, A.W.A. Murray and C. Goss, 1992: Krill biomass in Area 48 and Area 58: recalculations of FIBEX data. Selected Scientific Papers (SC-CAMLR-SSP/9), CCAMLR, Hobart, Australia, 157-181.

Trathan, P.N., J.L. Watkins, A.W.A. Murray, A.S. Brierley, I. Everson, C. Goss, J. Priddle, K. Reid, P. Ward, R. Hewitt, D. Demer, M. Naganobu, S. Kawaguchi, V. Sushin, S.M. Kasatkina, S. Hedley, S. Kim and T. Pauly, 2001: The CCAMLR-2000 Krill Synoptic Survey-a description of the rationale and design. CCAMLR Science, 8, 1-23.

Vaughan, D.G. and S.M. Doake, 1996: Recent atmospheric warming and retreat of ice shelves on the Antarctic Peninsula. Nature, 379, 328-331.

Watkins, J.L. and A.S. Brierley, 2000: Verification of acoustic techniques used to identify Antarctic krill. ICES Jour. Mar. Sci., 53(2), 339-344.

White, W.B. and R.G. Peterson, 1996: An Antarctic circumpolar wave in surface pressure, wind, temperature, and sea-ice extent. Nature, 380, 699-702.

Witek, Z., J. Kalinowski and A. Grelowski, 1988: Formation of Antarctic krill concentrations in relation to hydrodynamic processes and social behavior. In: Antarctic Ocean and Resources Variability. D. Sahrhage, ed., Springer Verlag, Berlin, 237-244.

Zane, L., L. Ostellari, L. Maccatrozzo, L. Bergelloni, B. Battaglia and T. Patarnello, 1998: Molecular evidence for genetic subdivision of Antarctic krill (Euphausia superba Dana) populations. Proceedings of the Royal Society of London, Series B: Biological Sciences, 265(1413), 2387-2391.

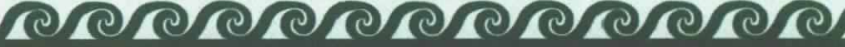

Breaking Waves provides an outlet for short papers describing novel approaches to multidisciplinary problems in oceanography. These papers present syntheses of findings that have the potential to move the field of oceanography forward or in new directions.

Papers should be written in a style that is both concise and accessible to a broad readership. While papers should be thought provoking for the professional oceanographer, they should also be written in a manner that is engaging for the educated nonprofessional. As in other sections of Oceanography, we encourage the use of color figures to help illustrate a paper's main points and add to its aesthetic appeal.

The Associate Editor for Breaking Waves is Charles H. Greene (chg2@comell.edu), Department of Earth and Atmospheric Sciences, Cornell University, Ithaca, New York 14853. Authors should submit a brief e-mail message outlining their ideas for papers prior to actual manuscript preparation.
} 